\title{
Anion-Exchange Synthesis of Dysprosium Oxide Nanocrystalline Powders
}

\author{
Gennady L. Pashkov, \\ Natalia P. Evsevskaya, Yelena V. Linok, \\ Marina V. Panteleeva and Galina N. Bondarenko* \\ Institute of Chemistry and Chemical Technology SB RAS \\ FRC "Krasnoyarsk Science Center SB RAS" \\ 50/24 Akademgorodok, Krasnoyarsk, 660036, Russia
}

Received 20.07.2016, received in revised form 08.08.2016, accepted 01.09.2016

The synthesis of the dysprosium oxide by using the anion exchange precipitation of the precursor from the nitrate solutions by strong base anion resin $A V-17-8$ followed by heat treatment at $850{ }^{\circ} \mathrm{C}$. It is found that is necessary to carry out the synthesis using AB-17-8 in $\mathrm{CO}_{3}$-form. The products have been characterized by IR spectroscopy, XRD, TEM. It was determined that the resulting product is $\mathrm{Dy}_{2} \mathrm{O}_{3}$, containing no impurities of other phases, and the particles have a size of 20-30 $\mathrm{nm}$.

Keywords: dysprosium oxide, exchange resin, synthesis, nanoparticles.

DOI: $10.17516 / 1998-2836-2016-9-3-371-376$.

(C) Siberian Federal University. All rights reserved

* Corresponding author E-mail address: tnm@icct.ru 


\title{
Анионообменный синтез наноразмерных порошков оксида диспрозия
}

\author{
Г.Л. Пашков, Н.П. Евсевская, \\ Е.В. Линок, М.В. Пантелеева, Г.Н. Бондаренко \\ Институт химии и химической технологии СО РАН \\ ФИЦ «Красноярский научный центтр СО РАН» \\ Россия, 660036, Красноярск, Академгородок, 50/24
}

Изучен процесс анионообменного синтеза оксида диспрозия путем осаждения прекурсора из нитратных растворов с помощью сильноосновного анионита AB-17-8 с последующей термообработкой при $850{ }^{\circ} \mathrm{C}$. Установлено, что осаждение необходимо вести, используя AB-17-8 в СО- -форме. Прекурсор и конечный продукт охарактеризованы методами ИКспектроскопии, РФА и ПЭМ. Определено, что полученный продукт отвечает составу $D y_{2} O_{3}$, не содержит примесей других фаз, а его частицы имеют размер 20-30 нм.

Ключевые слова: оксид диспрозия, анионит, синтез, наночастицьы.

Нанокристаллические порошки оксидов редкоземельных металлов широко применяются при создании магнитных материалов. Оксид диспрозия $\mathrm{Dy}_{2} \mathrm{O}_{3}$ используют в производстве сверхмощных постоянных магнитов, при получении люминофоров, каталитических систем и нейтронопоглощающих материалов $[1,2]$. Среди различных химических методов синтеза оксида диспрозия (золь-гель, осаждение, гидротермальный и проч.) можно выделить анионообменный, который уже на стадии получения прекурсоров определяет возможности для управления размерными, фазовыми и структурными характеристиками. Анионообменное осаждение - реакционно-ионообменный процесс, включающий две сопряжённые гетерогенные реакции: анионный обмен между низкомолекуляным электролитом (раствор) и сшитым полиэлектролитом (анионит) и осаждение малорастворимого соединения металла из раствоpa [3]. Осаждение ионов диспрозия можно суммарно описать уравнением

$$
3 \mathrm{RX}+\mathrm{DyA}_{3} \rightarrow 3 \mathrm{RA}+\mathrm{DyX}_{3} \downarrow
$$

где $\mathrm{R}$ - матрица анионита; $\mathrm{X}-\mathrm{OH}^{-}$или $1 / 2 \mathrm{CO}_{3}^{2-} ; \mathrm{A}=\mathrm{NO}_{3}{ }^{-}$.

Цель работы - выявление закономерностей направленного синтеза порошков $\mathrm{Dy}_{2} \mathrm{O}_{3}$ путем анионообменного осаждения диспрозия из водных растворов с последующей термообработкой полученного прекурсора и установление свойств образующихся оксидных материалов.

\section{Экспериментальная часть}

Реактивы, используемые в работе, имели классификацию «ч.д.а.» и дальнейшей очистке не подвергались.

В работе применялся сильноосновный анионит АВ-17-8 (ГОСТ 20301-74) в гидроксидной и карбонатной формах, содержащий четвертичные триметиламмониевые группы основного 
характера. Перевод анионита $\mathrm{AB}-17-8$ из хлоридной в ОН- и $\mathrm{CO}_{3}-$ формы осуществляли по методикам [3, 4], определение полной обменной емкости (ПОЕ) анионита проводили по $0,1 \mathrm{M} \mathrm{HCl}$, как описано в [5].

Подготовленную навеску анионита, взятого в полуторном избытке (превышение количества молей его функциональных групп над количеством молей диспрозия в растворе с учетом стехиометрии реакции 1), приводили в контакт с 30 мл 0,25 M раствора $\mathrm{Dy}\left(\mathrm{NO}_{3}\right)_{3}$ при комнатной температуре и постоянном перемешивании $\left(120\right.$ об/ $\left.\mathrm{c}^{-1}\right)$ в течение 40 мин. Затем анионит отделяли, пропуская смесь через сито с диаметром отверстий 0,25 мм. Для отделения осадка (прекурсора) проводили центрифугирование, полученный осадок высушивали при $100{ }^{\circ} \mathrm{C}$ и подвергали обжигу при $850{ }^{\circ} \mathrm{C}$ в течение 2 ч.

Рентгенофазовый анализ образцов проводили методом порошков (порошки помещали на монокристалл кремния) в интервале углов $0^{0}<2 \Theta<80^{0}$, время накопления импульсов 2 с (X'Pert PRO PIXcel фирмы PANalytical, излучение $\mathrm{CuK \alpha}$, длина волны 1,5405980 А̊). ИК-спектры записывали на спектрометре Vector 22 фирмы Bruker, образцы прессовали в виде дисков со спектрально чистым КВr. Исследования методом ПЭМ выполнены на просвечивающем электронном микроскопе HT-7700, Hitachi (Япония).

\section{Обсуждение результатов}

Полноту анионообменного осаждения диспрозия определяли кондуктометрическим методом путем контроля электропроводности системы «раствор нитрата диспрозия - анионит». В ходе осаждения анионы раствора переходят в фазу анионита, а катионы связываются в малорастворимое соединение, что приводит к снижению электропроводности раствора. На рис. 1 (кривая 1) видно, что электропроводность системы при использовании AB-17-8 в карбонатной форме снижается до нуля, что говорит о практически полном осаждении $\mathrm{Dy}^{3+}$. В то же время при использовании АВ-17-8 в ОН-форме (рис. 1, кривая 2) уменьшение значения электропроводности мало, следовательно, осаждения не происходит, что, вероятно, является следствием образования плотного поверхностного осадка на зернах анионита, который плохо отслаивается и препятствует дальнейшему протеканию ионного обмена [3].

Итак, очевидно, что для синтеза прекурсора необходимо использовать анионит АВ17-8 в $\mathrm{CO}_{3}$-форме. По данным РФА, прекурсор рентгеноаморфен, поэтому для его характеризации использовали метод ИК-спектроскопии. На ИК-спектре прекурсора (рис. 2) можно отметить широкую полосу поглощения (п.п.) $3424 \mathrm{~cm}^{-1}$, свидетельствующую о наличии в его составе $\mathrm{OH}-$ групп; две интенсивные п.п. 1516 и $1396 \mathrm{~cm}^{-1}$, соответствующие $v_{3}$ колебаниям $\mathrm{CO}_{3}{ }^{2-}$-групп, п.п. при 1078, 842 и $746 \mathrm{~cm}^{-1}$ можно отнести, соответственно, к $v_{1}, v_{2}, v_{4}$ колебаниям $\mathrm{CO}_{3}{ }^{2-}$-групп [6]; п.П. при $689 \mathrm{~cm}^{-1}$ относится к валентным колебаниям связи Dу-О. По-видимому, образец представляет собой основный карбонат диспрозия.

По результатам ПЭМ (рис. $3 a, \sigma)$ прекурсор состоит из частиц близкой к сферической формы размером 20-30 нм. После термообработки при $850{ }^{\circ} \mathrm{C}$ в течение 2 ч прекурсор кристаллизуется в $\mathrm{Dy}_{2} \mathrm{O}_{3}$ кубической модификации (ICCD database, file 86-1327), что подтверждено РФА (рис. 4). На дифрактограмме $\mathrm{Dy}_{2} \mathrm{O}_{3}$ отсутствуют рефлексы других фаз. Размер частиц $\mathrm{Dy}_{2} \mathrm{O}_{3}$, несмотря на довольно высокую температуру обжига $850{ }^{\circ} \mathrm{C}$, практически не отличается от размера частиц прекурсора (рис. 3), т.е. равен 20-30 нм. 


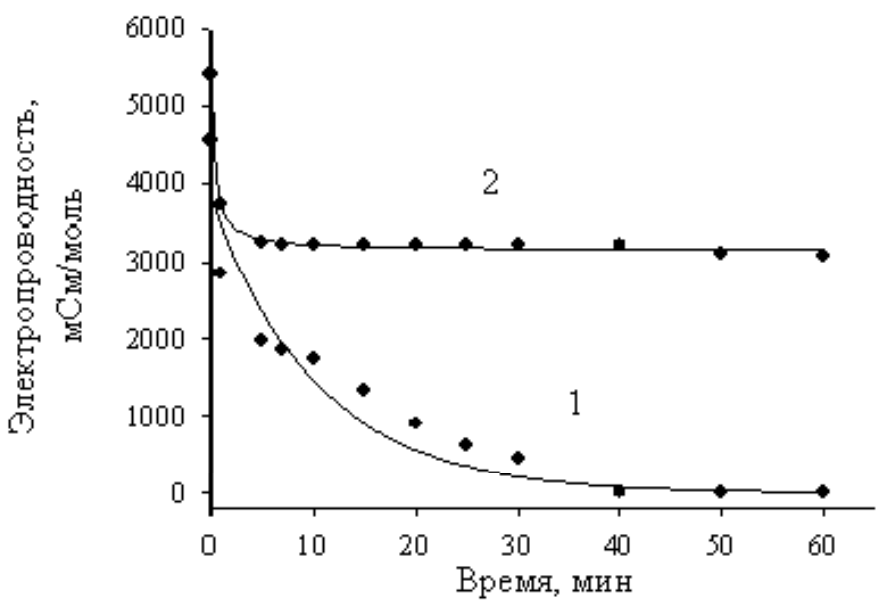

Рис. 1. Зависимость электропроводности системы «раствор нитрата диспрозия - анионит» при анионообменном синтезе от времени при использовании анионита АВ-17-8 в ОН- (кривая 2) или СО форме (кривая 1)

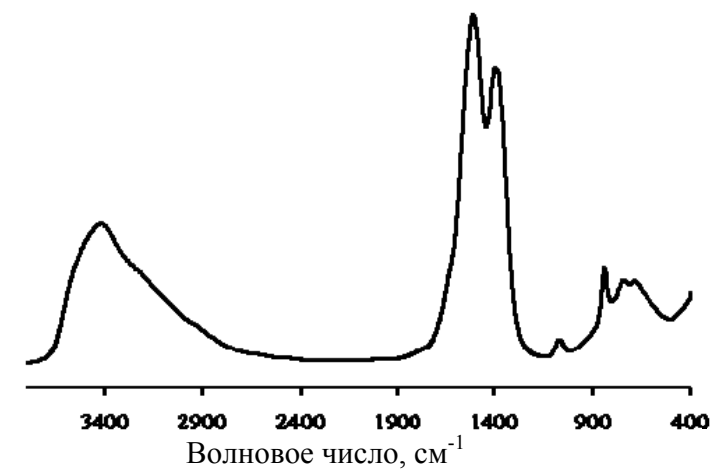

Рис. 2. ИК-спектр прекурсора

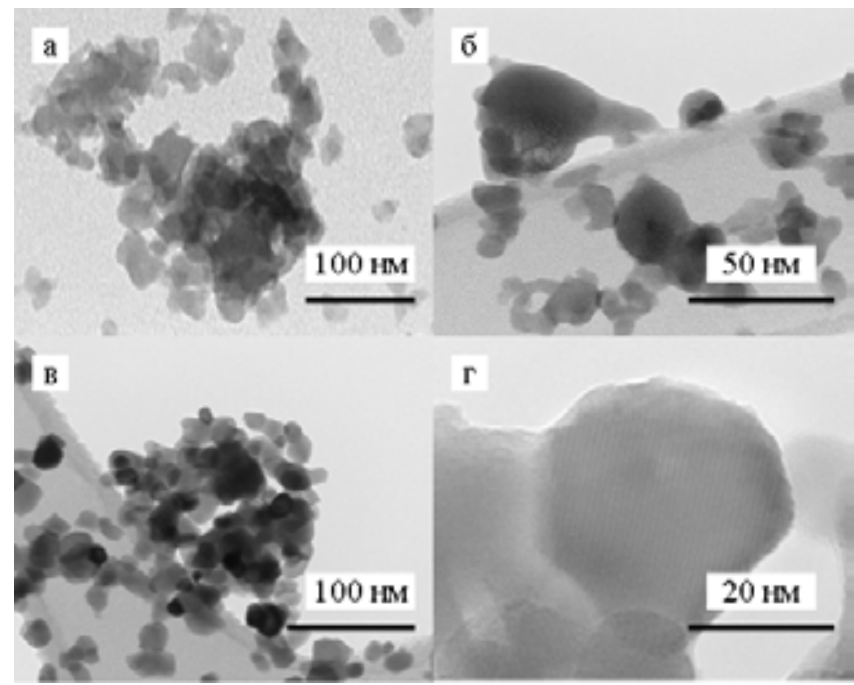

Рис. 3. Микрофотографии ПЭМ; а, б - прекурсора; в, г- $\mathrm{Dy}_{2} \mathrm{O}_{3}$ 


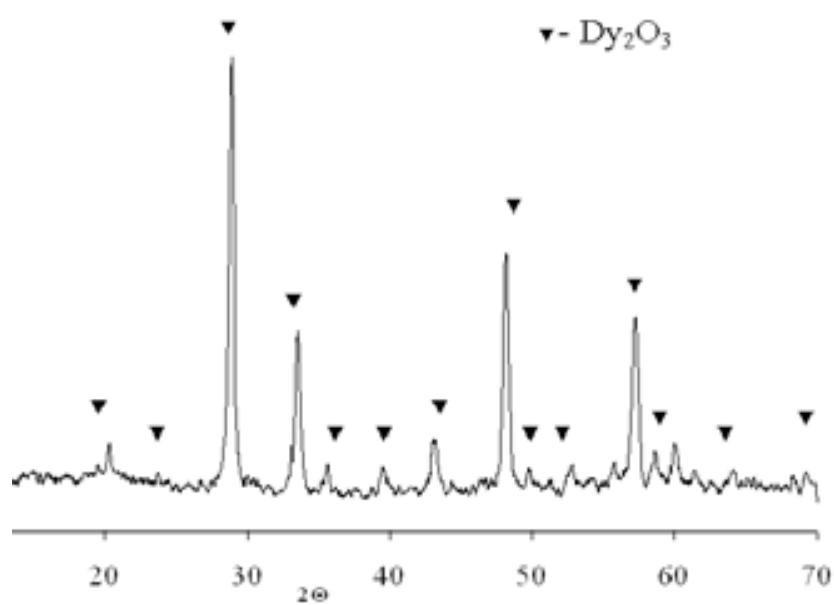

Рис. 4. Дифрактограмма образца $\mathrm{Dy}_{2} \mathrm{O}_{3}$, полученного после термообработки прекурсора

\section{Выводы}

В работе предложен анионообменный метод синтеза нанокристаллического порошка $\mathrm{Dy}_{2} \mathrm{O}_{3}$ из нитратных растворов с помощью анионита AB17-8 с последующей термообработкой прекурсора при $850{ }^{\circ} \mathrm{C}$. Установлено, что для синтеза прекурсора необходимо использовать анионит АВ17-8 в $\mathrm{CO}_{3}$-форме.

Продукт $\mathrm{Dy}_{2} \mathrm{O}_{3}$ состоит из однородных частиц, по форме близкой к сферической, размером 20-30 нм и может быть использован для создания функциональных оксидных материалов.

Работа выполнена при поддержке проекта II.2П/V.46-5 программы фундаментальных исследований СО РАН и программы ОХНМ РАН (№ 7) «Новые химико-технологические процессы с созданием опытных партий».

Электронно-микроскопические исследования и регистрация ИК-спектров выполнены на оборудовании Центра коллективного пользования ФИЦ КНЦ СО РАН.

\section{Список литературы}

1. Kanga J.G., Gwagb J. S., Sohn Y. Synthesis and characterization of $\mathrm{Dy}(\mathrm{OH})_{3}$ and $\mathrm{Dy}_{2} \mathrm{O}_{3}$ nanorods and nanosheets. Ceramics International 2015. Vol. 41, P. 3999-4006

2. Рисованый В.Д., Захаров А.В., Муралева Е.М. Новые перспективные поглощающие материалы для ядерных реакторов на тепловых нейтронах. Bопросы атомной науки и техни$\kappa и$ 2005. T. 86, C. 87-93. [Risovany V.D., Zakharov A.V., Muraleva E.M. New advanced absorbing materials for the nuclear thermal reactors. Problems of Atomic Science and Technology 2005. Vol 5 P. 87-93. (In Russ.)]

3. Сайкова, С. В. Реакционно-ионообменные прочессы извлечения иветных металлов и получения дисперсных материалов : дис. ... д-ра хим. наук : 05.17.01 Красноярск, 2014. - 303 с. [Saykova S.V., Reactive ion exchange processes of extraction of non-ferrous metals and obtaining of the particulate materials. Doctoral dissertation, Krasnoyarsk, 2014, 303 p. (In Russ.)] 
4. Pashkov G.L., Saikova S.V., Panteleeva M.V., Linok E.V. Ion-exchange synthesis of $\alpha$ modification of nickel hydroxide. Theoretical Foundations of Chemical Engineering. 2014. Vol. 48(5), P. 671-676.

5. Pashkov G. L., Saikova S.V., Panteleeva M.V., Linok E.V., Evsevskaya N. P., Bondarenko G. N., Zhizhaev A. M., Tarasova L. S. Anion-exchange synthesis of yttrium-aluminum garnet powders. Glass and Ceramics. 2016. Vol. 73 (3) P. 107-110.

6. Salavati-Niasari M., Javidi J., Davar F. Sonochemical, Fazl A. A. Sonochemical synthesis of $\mathrm{Dy}_{2}\left(\mathrm{CO}_{3}\right)_{3}$ nanoparticles and their conversion to $\mathrm{Dy}_{2} \mathrm{O}_{3}$ and $\mathrm{Dy}(\mathrm{OH})_{3}$ : Effects of synthesis parameters. Journal of Alloys and Compounds. 2010 . Vol. 503. P. 500-506. 